\title{
Chapter 12 \\ Developing Assessment for Learning \\ Practice in a School Cluster: Primary \\ and Secondary Teachers Learning \\ Together
}

\author{
Sue Swaffield, Roszalina Rawi and Amanda O'Shea
}

\begin{abstract}
The nature of professional development for the sustained implementation of assessment for learning (AfL) is a pressing and perennial challenge. So too is pupil transfer between schools. This chapter explores how cross-phase collaborative learning supports the development of AfL practice. Teachers from a secondary school and its seven feeder primary schools worked together using three principles of AfL derived from previous research to assist analysis of existing practices, to plan developments, and to scaffold discourse. The value of this approach was revealed by data gathered through questionnaires and interviews with teachers in the working group, along with observations of workshops at which participant teachers shared their work with other teachers, who were also invited to complete a questionnaire. It is suggested that AfL, underpinned by the principles of making learning explicit, promoting learning autonomy, and focusing on learning, can act as a pedagogical unifier across age ranges and subjects and thus aid pupil transfer. Recommendations are proposed for teachers, policymakers, and particularly school leaders.
\end{abstract}

\subsection{Introduction}

The challenge at the heart of the project discussed in this chapter is professional development for the sustained implementation of assessment for learning (AfL). Specifically, the research aimed at understanding how cross-phase collaborative learning between primary and secondary teachers supports the development of AfL practice. Pupils' learning, both in discrete subjects and in learning how to learn, occurs in many contexts with many different teachers over their school career.

S. Swaffield $(\bowtie) \cdot$ R. Rawi

University of Cambridge, Cambridge, UK

e-mail: ses42@cam.ac.uk

\section{A. O'Shea}

University of Northampton, Northampton, UK

(C) Springer International Publishing Switzerland 2016

D. Laveault and L. Allal (eds.), Assessment for Learning: Meeting the Challenge

of Implementation, The Enabling Power of Assessment 4,

DOI 10.1007/978-3-319-39211-0_12 
Whilst AfL practices should be adapted to age ranges and subjects, they also need to be complementary and sustained so that learners experience coherence across settings and progression over time. Implementation is therefore not just about the practices of individual teachers but also about congruence throughout the primary and secondary schools children attend.

Coherence with appropriate adaptations to context can be achieved through a shared understanding of fundamental issues and adherence to common underlying principles. Swaffield (2011) argued that not all practices purported to be AfL support pupils in learning how to learn, because the practices are not in accordance with three key principles. These principles were formulated by a large multiuniversity team working with over 40 schools in England (James et al. 2007) and can be summarised as: making learning explicit, promoting learning autonomy, and focusing on learning rather than grades (James and Pedder 2006).

Application of AfL principles across a family of schools can be promoted by teachers from different schools and subject specialisms working together to improve their AfL understanding and practices. The work reported here involved collaboration among serving teachers, school leaders, and university researchers.

The next section draws on research literature to consider issues relating to teachers' collaborative professional learning and the development of classroom practice, the implementation of AfL, and pupils' transfer from primary to secondary school. This is followed by an overview of the particular project that provided the empirical data, and details of data gathering. Findings are then presented and discussed in advance of a conclusion that includes four themes arising from the cross-phase professional development work, an outline of some of the challenges for implementation of AfL, and recommendations for school leaders, teachers, and professional development policymakers.

\subsection{Background Issues}

\subsubsection{Collaborative Professional Learning}

The importance of teachers' collaborative professional learning for improving the quality of teaching and learning in schools has been widely recognised, for example, by Borko (2004), Little (2005), Katz and Earl (2010), Pedder and Opfer (2011), and Willis et al. (2013). Teachers have long worked and learned together in groups variously termed 'professional learning communities,' 'collaborative learning communities' (Cooper and Boyd 1998), 'communities of practice' (Wenger 1998), and 'teacher learning communities' (Wiliam 2007a). In essence, while working to improve their practice, professionals learn together through interacting regularly, sharing resources, reflecting on practice, reviewing outcomes, and providing feedback and support for each other. Collaborative learning is grounded in practice, and those involved have been found to be more dedicated in 
their efforts to improve teaching and learning (Rosenholtz 1989). Efforts to improve teaching practices should centre on peer collaboration and concerted discussions in teacher learning communities (Darling-Hammond 1996; Clausen et al. 2009; Wiliam 2007a). Clausen et al. (2009) pointed to the importance of a positive start and early success to motivate members and sustain their undertakings.

Putnam (2000) and Woolcock (2001) considered three forms of social capitalbonding, bridging, and linking. Strong support and empathy from colleagues who face similar challenges help teachers in learning communities build bonding social capital, while extended networking can develop bridging social capital (Putnam 2000), giving teachers access to valuable ideas and information. Wiliam (2007b) suggested that the most promising approach for implementing effective formative assessment practices is through teachers learning in small, building-based groups. These he contrasted with teachers meeting others from different schools, characterised as a good way to get new ideas about AfL, but described as 'sources of information, not sources of change in teacher behaviour' (Wiliam 2007b, p. 40). Smith (2011) suggested that a major disincentive to teachers' professional development in AfL is the lack of competence of teacher educators in AfL. In order for AfL to be common assessment practice in schools, there needs to be improvement in processes at various levels of the education system. In a community of practice, novices can connect with experts, and academics with practitioners (Lave and Wenger 1991). Woolcock (2001) considers these vertical connections as linking social capital that allow teachers to leverage wider resources from beyond their usual peer groups.

\subsubsection{Teachers Innovating Practice in AfL}

Reviews and research, for example by Black and Wiliam (1998), Gardner (2006), and Earl (2012), indicated that AfL has the potential to make a substantial positive impact upon learning. However, classroom assessment practice can be extremely difficult to change. Partly, the difficulties lie in the translation of those theories into practice.

Wiliam (2009) contended that a useful model of development is to enable teachers to see what AfL means in practice and to understand what will make the greatest impact upon learning. Teachers need practical techniques for achieving the principles, modelled by practitioners in contexts that are relevant to them, alongside the flexibility to innovate with those techniques. Gardner (2010) argued that teacher self-agency is a key to change that is more powerful than notions of 'theory-first or practice-first' (p. 133). Teachers need to be supported in developing aspects of their practice as a personal agenda.

Sato et al. (2005) described two very different teachers developing AfL within their own contexts. This research and that of others (e.g. James et al. 2007) demonstrated that teachers' practices are entwined with their beliefs and values. While teachers might try something new, it is likely to be discarded if it does not fit 
within their personal modes and values of teaching. Sato et al. (2005) concluded that such changes do not come easily because they are essentially personal in nature. Implementing new ideas led nevertheless to changes in teachers' underlying beliefs and assumptions about teaching and learning. Long-term sustainable change arose from valuing continued reflection and experimentation with colleagues over time so that those innovations became internalised.

Suurtamm et al. (2010) similarly concluded that collaborative professional development (CPD) was instrumental in developing practice since it enabled teachers to network with others. Where such networks and communities have support, time, and space, they have proved successful in developing social capital with mutual trust and support, and intellectual capital with ideas and practice (James and McCormick 2009). Networks are an opportunity to develop bonding social capital between groups of teachers within similar contexts and bridging social capital between teachers of different key stages and subjects.

In terms of time, Wiliam (2009) argued that teacher learning communities should ideally run for at least two years, with groups of between eight and twelve teachers meeting approximately once a month being the most effective. Meetings should focus on allowing time for each teacher to feedback to the group on their classroom innovations but also include an element of new study to inform them about AfL and encourage future action planning.

\subsubsection{Issues with Implementing AfL}

One crucial element to implementing effective AfL lies in its conception and definition. However, while some teachers conceptualise AfL in terms of pupil autonomy, others focus on monitoring performance (Hargreaves 2005). James and Pedder (2006) argued that teachers do not necessarily practise what they most value in assessment, which sometimes leads to a focus on learner performance rather than autonomy. It was this research as part of the Learning How to Learn project that identified the three dimensions to AfL practices mentioned above: promoting pupil autonomy, making learning explicit, and focusing on learning. The difficulty for teachers was in balancing the need to monitor performance with other practices in assessment that might improve learning.

Tierney's (2006) review of influences on changing assessment practices highlighted time as a considerable factor. There needs to be the will and acceptance of the long time-frame associated with implementing reform when the impact on learning may not be immediately realised. Time is necessary for changes to become embedded within practice, yet there is often pressure to move on to new initiatives. Embedding change in assessment practices is not simple and requires support from school leadership (Swaffield and MacBeath 2006; Smith and Engelsen 2013). Kellard et al. (2008) cite the importance of support and enthusiasm from schools' senior leadership in terms of practical time and resources but also as enablers to a bottom-up approach towards change. 


\subsubsection{Transfer}

Galton et al. (2003) used the term transfer in the context of addressing research that involves pupil transfer between schools, rather than transitions between years within the same school. According to Mizelle (2005) an effective framework to facilitate such transfer should include a 'vertical team' (p. 59) that includes teachers and administrators across grade levels and schools discussing how to better align curriculum. Teacher intervention in the form of formative assessment activities that enhance self-esteem and motivation to learn can also ease the transfer issues faced by students (Craven et al. 1991; Ginsburg-Block et al. 2006; Miller and Lavin 2007). Beaumont et al. (2014) acknowledged the difficulty and challenges of transfer from secondary to higher education in respect of assessment practices and feedback.

Issues of pupil transfer between schools, innovating and implementing AfL, and teacher collaborative learning were all central to the project discussed in this chapter.

\subsection{Project}

\subsubsection{Background and Project Details}

The project involved a semi-rural secondary school (pupils aged between 11-16 years) and its seven feeder primary schools (pupils aged between 4-11 years), which together have approximately 130 teachers. The cluster has a long history of collaboration, and systemic developments in recent years (for example the creation of Teaching Schools Alliances) have seen additional opportunities and renewed commitment from senior leaders to enabling ongoing liaison among teachers. Teachers working together on projects with specific foci is one way in which the perennial aim of supporting pupils throughout their schooling is addressed.

The schools have close links with the local university, particularly through teacher education programmes (both initial and continuing), and research-focused partnerships. A senior leader of the secondary school with responsibility for cluster liaison secured a small amount of funding and approached the university to contribute to a cluster AfL project. In liaison with the school senior leader, the university colleague (first author of this chapter) facilitated professional development activities, fed in research, supported the teachers in elements of enquiry within the professional development activities, and researched the process.

The project, with its broad aim of raising attainment through AfL, was conceived at a cluster steering meeting as a way of building on the benefits of recent 
partnership working among the schools. It lasted one academic year, starting and finishing with a joint staff meeting for all the teachers in the cluster. Senior school leaders (primary and secondary) addressed the joint staff meeting at the beginning of the year, explained the particular focus on feedback, and the plans for the whole year. These involved a working group of volunteer teachers drawn from all the schools meeting periodically, and a conference at the end of the year for all teachers to learn from the working group. The university colleague then invited the teachers to consider their AfL feedback practices in the light of pertinent research, in particular three principles of AfL practice (James and Pedder 2006), and outlined a framework for collaborative working. Subsequently, more teachers volunteered for the working group than could be accommodated, so the school leaders selected 23 (12 primary and 11 secondary) school teachers representing a variety of teaching experience, age ranges taught, and (in the secondary school) subject specialisms. The working group included the teaching head of one of the primary schools.

The working group, facilitated by the university colleague, met for two hours on each of four occasions, planning together, reporting progress, giving one other feedback, and considering published research (see Table 12.1).

The three AfL principles introduced at the joint staff meeting-making learning explicit, promoting learning autonomy, and focusing on learning rather than grades (James and Pedder 2006; James et al. 2007) —were referred to repeatedly and became part of the discourse providing a common language for discussing disparate practices. The five cross-phase subgroups formed around teachers' specific interests focusing on aspects of feedback in different contexts (as detailed in Table 12.2).

Table 12.1 Full staff and working group meetings

\begin{tabular}{|c|c|c|}
\hline Timeline & Type of meeting & Purpose \\
\hline \multirow{2}{*}{$\begin{array}{l}\text { September } \\
2013\end{array}$} & \multirow{2}{*}{$\begin{array}{l}\text { Cluster full staff } \\
\text { meeting }\end{array}$} & Introducing project and AfL principles \\
\hline & & Inviting volunteers for working group \\
\hline \multirow{3}{*}{$\begin{array}{l}\text { October } \\
2013\end{array}$} & \multirow{8}{*}{$\begin{array}{l}\text { Working group } \\
\text { meetings }\end{array}$} & Details of project purpose and process \\
\hline & & Identifying specific foci and forming subgroups \\
\hline & & $\begin{array}{l}\text { Planning including initial data gathering from } \\
\text { pupils/colleagues }\end{array}$ \\
\hline \multirow{2}{*}{$\begin{array}{l}\text { November } \\
2014\end{array}$} & & Findings and examples from international research \\
\hline & & Sharing practice, plans, and progress \\
\hline $\begin{array}{l}\text { February } \\
2014\end{array}$ & & Subgroups reporting and feeding back to each other \\
\hline \multirow[t]{2}{*}{ April 2014} & & Sharing developments \\
\hline & & Planning for joint staff meeting \\
\hline \multirow[t]{2}{*}{ June 2014} & \multirow[t]{2}{*}{$\begin{array}{l}\text { Cluster full staff } \\
\text { conference }\end{array}$} & $\begin{array}{l}\text { Working group subgroups leading workshops, with } \\
\text { explicit reference to three AfL principles }\end{array}$ \\
\hline & & Plenary discussion \\
\hline
\end{tabular}


12 Developing Assessment for Learning Practice in a School Cluster ...

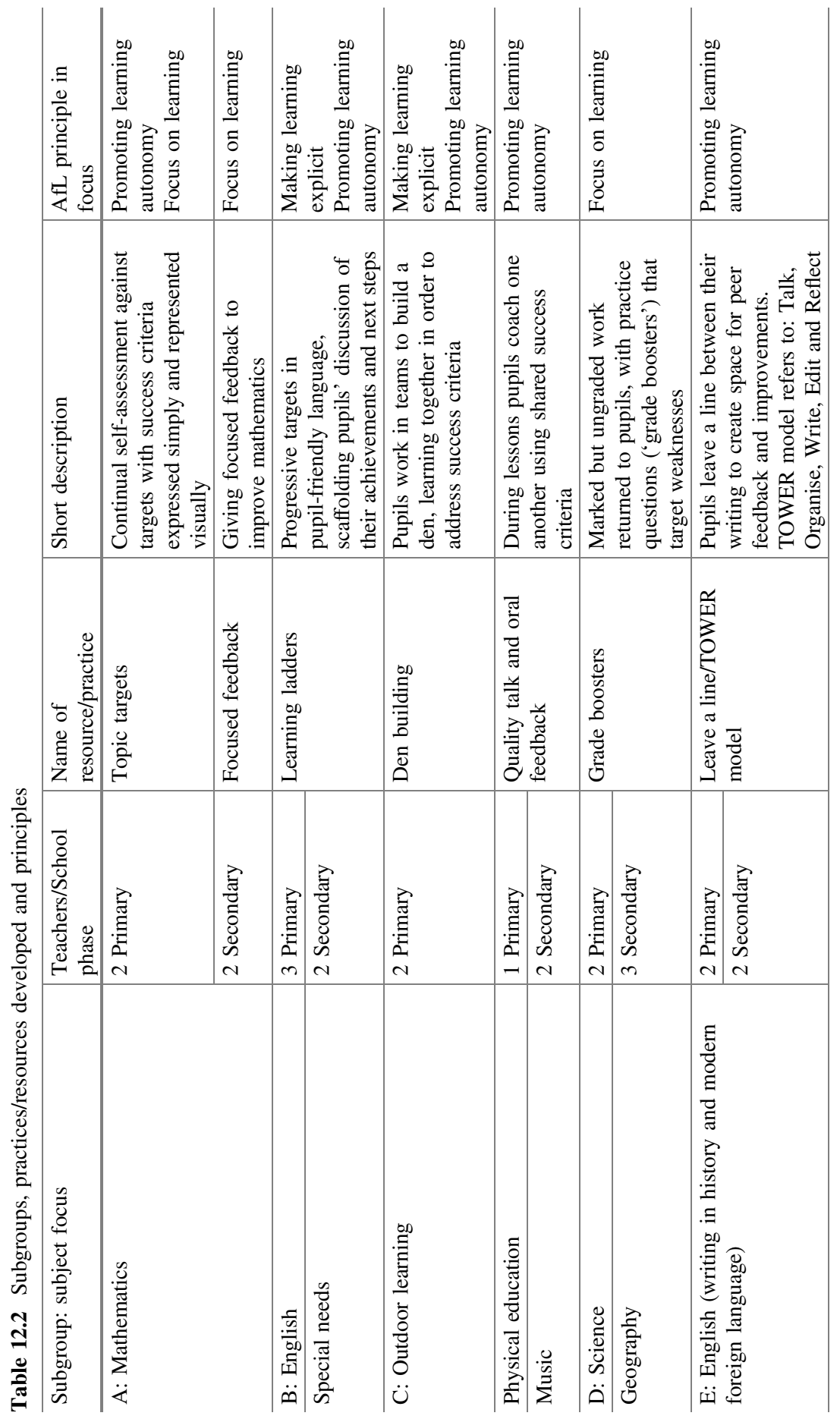




\subsubsection{Researching Cross-Phase Professional Development}

Data were generated towards the end of the year through questionnaires, interviews, and observations, and evidence generated naturally during the course of the project was also analysed. Each of the workshops at the end of year conference was observed, with attention given to indicators of the working relationship among the subgroup members. Two open response questionnaires were used. All the teachers present at the final full staff conference were invited to complete a questionnaire reflecting on their learning (41 returned-approximately half of those present, excluding the working group). Members of the working group completed a different questionnaire that, among other things, sought their views on the benefits and challenges of cross-phase collaboration (13 returned). Interviews were also conducted with five working group members, following up points in their questionnaires and exploring other aspects of the project.

Interviews were taped and transcribed, questionnaire data entered onto spread sheets, and observations recorded on a proforma. Data analysis was conducted by the three researchers/authors, first separately then together comparing interpretations.

\subsection{Findings}

\subsubsection{Collaboration Generates Resources and Practices to Improve Learning}

The stimulus and opportunities offered by sharing practice in learning communities generated developments that ultimately impacted upon learning. Practices developed and resources created through collaboration among teachers were trialled and improved before being showcased at the cluster conference. The main developments are outlined in Table 12.2, together with the subject focus, numbers of teachers, school phase, and related principle(s). Each group had specific subject orientations and most generated more than one practical resource.

A key feature common to the work of groups A (subject focus Mathematics), B (subject focus English), and C (subject focus outdoor and practical learning) was the development of pupil self-assessment through their discussion of learning, achievements, and next steps in relation to clearly expressed success criteria. Group $\mathrm{C}$ and group E (English) both focused on peer assessment, either during the course of practical activities or, in the case of English, after a piece of writing had been drafted. Teachers in groups D (Science and Geography), along with the secondary colleagues in group A (Mathematics), concentrated on their response to pupils' work and developing ways for pupils to act on and learn from the feedback.

Teachers particularly appreciated innovations that had a clear impact on pupil learning and were adaptable across different age ranges and subjects. By collaborating and building on one another's ideas and practices, teachers found they did 
not have to start from scratch and could trial new approaches with the confidence that they had others' support. Teachers' collective experiences with AfL enabled them to be mutual 'sounding boards' when discussing new ideas and to 'bounce ideas off each other' (Headteacher, primary school).

Through sharing teaching approaches and experiences, which led to key insights about AfL, project participants were able to improve their practice and draw the pupils themselves into the processes of assessment. For example, one primary school teacher said that the project had been tremendously helpful: as a classroom teacher he had improved the quality of his marking and feedback, and as a leader he ensured whole-school initiatives were clearly focused on learning (rather than performance). Another teacher reported how he had been having difficulty with trying to improve writing in his primary classroom, and it was through working with a group member from the secondary school that he had found a solution to the problem.

Project teachers were committed to using the practices and resources they had created and to developing the ideas even further. Feedback from colleagues who attended the conference was also very encouraging with many reporting that they were excited at the prospect of implementing new approaches in their classrooms.

\subsubsection{Collaboration Aids Appreciation of Others' Contexts and Has an Affective Dimension}

Teachers admitted that prior to joining the project they had very little knowledge of one another's curricula and appreciated the opportunities the project afforded. They made links between what was occurring in quite different classroom settings, gained an understanding of how the same AfL strategy can be developed in both primary and secondary schools, and how teachers in both contexts can effectively support students' learning. For example, a secondary school teacher observed that he had developed a much clearer understanding of the prior experience pupils brought with them from primary school. These insights allowed teachers to plan their teaching more appropriately by focusing on pupils' prior experiences of assessments, easing school transfer for pupils, and aiding their learning.

The value and utility of cross-phase understanding was appreciated, especially as a means to achieving consistency in approaches as well as ensuring that learning and challenge were maintained. For many of the teachers of all phases and subjects, it was the insight into the similarities and differences of using AfL that was felt to be useful in giving a new understanding of approaches and areas of learning.

Primary teacher: Although we only met up four times over the year, I think those four times listening to each other talk were really good. The fact that all of the staff have come back to school and said things like 'I love this idea that I saw.' or that 'I really like what (someone) was saying about this.' Already that shows that it has improved understanding across phases. 
One group observed each others' teaching across different settings to learn more about the different contexts, which was highly valued by all concerned. A primary school teacher commented that working cross-phase was 'a really good idea' as there was 'a sense of community amongst all schools.' The conference extended this opportunity, albeit to a more limited extent, to all the cluster's teachers. They learnt from colleagues, novice and experienced alike, who were teaching other age ranges and subjects.

Teachers appreciated the opportunity afforded by the working group to discuss and reflect on their assessment practices. A secondary school teacher shared that 'you do not have the opportunity to discuss your work with colleagues on a day-to-day basis because we (teachers) are all shut away in individual classrooms.' A sense of solidarity grew amongst teachers from different schools as they felt they were working in a collaborative, nonjudgemental way. For another teacher the project had helped develop a network of teacher colleagues, deepen understanding of principles underpinning assessment for learning, and reaffirm her moral purpose:

Primary teacher: You don't always have much time to see other people teach after your first year. I didn't really know what to expect from it, but what I've got out of it are the connections I've made with other people, reestablishing my understanding of why I'm doing what I'm doing.

Through sharing their AfL practices teachers felt affirmation for their own work and appreciation of the work of others. The collaboration increased empathy among teachers who reported feeling increased regard for colleagues in different subjects and age phases. Recognising the commonality of challenges faced-as exemplified by the comment 'there are similar issues between age groups but feedback is important throughout' — contributed to collegiality. Further evidence of the development of bridging social capital across teaching contexts came from a primary teacher who reflected on how useful it was 'to see someone who is a real expert in a subject area, but equally for the secondary school teachers [to see] we have so many different things in place to support so many different types of learners.' Secondary teachers were alerted to the depth of learning that takes place in primary schools, for example, in the quality and sophistication of children's writing.

Teachers also empathised and gave one another moral support when problems regarding AfL implementation (for example classroom time management, pressure of examinations) were shared. Being part of a learning community meant that teachers with less teaching experience could count on others and learn from their rich experiences of practising AfL. An early career primary teacher felt she 'really benefited from being in a group with really experienced teachers who appreciated the fact that it was my first year and I was a bit nervous and not as confident as the others. It was nice, because they really included me within the group.'

Project teachers who presented their work at the conference demonstrated a strong sense of teamwork and frequently referred to what they had achieved together. By the end of the year the groups were easy and familiar with one another, and teachers from different schools demonstrated an understanding of the disparate contexts in which their colleagues taught. Secondary school project teachers noted 
how much they learnt about being student-focused from the early-years teachers in their group, while primary school teachers reflected on how subject-specific practices in secondary classrooms could also be useful for younger pupils.

At the conference there were lively discussions during various workshops as colleagues learnt about the variety of AfL practice across the cluster of schools. For example, a secondary teacher was particularly impressed by the productive use of peer assessment with very young children, while another reported that she was struck by 'the difficulty of giving constructive feedback to KS2 students [pupils aged 7-11 years] for Maths.' In one of the workshops project teachers were very open and spoke passionately about how much they had learnt from working group members who taught in schools across the primary-secondary divide. Colleagues who heard this were excited, curious, and in agreement that the ideas shared were useful across all age ranges. They were genuinely interested in how they could incorporate ideas into their own classroom assessment practices.

Teachers also reported that the conference helped them appreciate that implementing AfL is challenging regardless of school sector, and that there are considerable similarities in practice: 'many teaching assessment strategies are crosscurricular and able to be used across the age ranges; primary and secondary have far more links that I realised.' The way project teachers had worked together to develop ideas, and then collaborated in demonstrating their feasibility during the conference workshops, helped their colleagues see that AfL methods they may have thought suitable for only a specific age or subject have much more extensive applicability.

\subsubsection{AfL Principles Transcend Differences, Provide a Common Language and Promote Coherence}

For some teachers, the applicability of AfL strategies across subjects and ages was a revelation in itself. Differences in AfL practice were seen positively when connections were made to the three over-arching principles of promoting autonomy, making learning explicit, and focusing on learning rather than grades. These three principles transcend variations in practice among teachers of different subjects and ages. Innovations were seen to have common underpinnings, while unfamiliar practices were analysed for the principles they met, and then 'struck a chord' (secondary school teacher). The three AfL principles were cited by most teachers as key to their learning and development during the project, with individuals commenting on how the principles 'really helped to clarify my thinking' and 'simplified thoughts' helping to streamline ideas for the successful implementation of AfL.

According to the project teachers, the AfL principles provided a common language and promoted coherence within the group. They helped teachers gain an insight into the similarities and differences in teaching and learning across the key stages, highlighting, for example, that quality feedback was an issue for many. A primary school teacher shared how his group decided to focus on improving 
writing quality: 'All members in the group sat together around a table and had a "long long" conversation on what we had been doing to try to improve the quality of writing across the levels.'

The group then used their collective experiences to develop an effective feedback system for writing which was transferable across the age ranges. This happened across many groups where teachers found that they could reflect deeply about their own AfL practice based on the three key principles by learning from colleagues who taught other subjects and levels.

A primary school headteacher who was in one of the working groups asserted that 'because staff vary in knowledge and understanding ... it's really important that from the beginning, you set down the base of what the expectation is of AfL.' The introduction of the three principles assisted teachers in focusing on what they sought to improve in their AfL practice. Many reported that they had made these principles key to all their lesson planning; comments included, 'the focus is entirely on the learning not grades, marks or levels, and is all the better because of it!' (secondary school teacher); and 'in my role as deputy head [the principles have] also made staff meetings I have led and other whole school initiatives more meaningful and focused' (Deputy headteacher, primary school). At the final conference, many of the other teachers commented positively on the principles, noting them as 'key aspects I need to develop' and saying they would be considering them in the future.

\subsubsection{Multi-School Collaboration Presents Practical Challenges}

Even though the project was supported by all the schools in the cluster, there were considerable practical difficulties. The main challenge was the perennial one of time, manifested in different ways. For individuals, balancing time between teaching and other commitments and duties, whist also trying to develop AfL practice and contribute to the project, was acknowledged as a particular challenge that was 'part of life as a teacher.' The two occasions when teachers from all the schools in the cluster met together took considerable planning and co-ordination, with everyone needing to commit to professional development activity at the same time in the same place. It is often hard to arrange a full staff meeting in a single school, much less for all the teachers from eight schools.

The four working group meetings required teachers from across the cluster to be able to meet together, necessitating close liaison and commitment. Similarly, enabling teachers to visit others' classes for peer observation and additional subgroup meetings required coordination and multiple layers of arrangements. Additional expenses were incurred when cover had to be provided for teachers who were absent from their classrooms. Nevertheless, the teachers who were able to visit others' classes considered it to be ' 100 times more useful than any other form of training or professional development' (Deputy headteacher, primary school). 
Teachers typically experience difficulties in finding the time and space to have professional conversations with colleagues in their own schools, let alone in other schools. Sometimes fleeting chances to communicate were grabbed, and partial solutions found, such as 'conversations' by email, but these had their own challenges and were seen by some as 'convoluted' when a 'quick chat' face-to-face would have been preferable.

Other pressures, such as those arising from external inspection and maternity leave, are not easily accommodated or necessarily foreseeable. Teachers from one school had to miss a group meeting since precedence had to be given to their own full staff meeting on an issue that had arisen, and with seven other schools involved it was not practical to rearrange the project meeting.

Nevertheless, despite the challenges high participation continued throughout the project. For at least one group member choice was a key factor in the success of the project, suggesting that teacher agency is crucial for making changes to practice. That agency includes the freedom to choose to participate and which practices to focus upon. For the teachers involved in the development project, it was this bottom-up choice that led to teams of teachers who were motivated towards making changes and working collaboratively.

Collaboration between such motivated teachers, all working to develop practice together, was highly valued and regarded as most beneficial to the extent that it was planned to continue with that model of CPD. The project's success and teachers' appreciation of its benefits generated the desire for more time to spend on this and similar professional development. The AfL project was only prioritised for one year, although the work linked closely to CPD foci in the following year when inter-school work concentrated on the implementation of a revised national curriculum and the associated guidance for ongoing assessment not to use grades. The secondary school also incorporated AfL into a new working group involving other teachers exploring how to help pupils develop a 'growth mindset.'

\subsection{Conclusion}

\subsubsection{Four Themes}

A number of conclusions may be drawn from the empirical data and can be grouped into four main themes:

- the benefits of cross-phase collaboration for developing AfL;

- the contribution of cross-phase professional development on AfL to pupil transfer;

- the value of principles to developing AfL practice in multiple settings;

- the role of leadership in supporting professional development across a cluster of schools. 
Working group members were unanimous in their appreciation of the opportunity for cross-phase professional development, the reasons for which included, but went well beyond, 'the positives of collaborative professional inquiry models' (Kennedy 2014, p. 692) increasingly found in contemporary literature. Learning with and from each other, appreciating differences, sharing and developing practices, and finding ways of improving pupils' learning were all highly valued by both primary and secondary teachers. This contrasts with Pedder and Opfer's (2011) findings that suggested secondary teachers' motivation for CPD participation is more likely to be career enhancement. The constituency of the working group resembled Lave and Wenger's (1991) depiction of a community of practice in that it included novices (newly qualified teachers), experts (senior teachers and school leaders), and academics, with all parties learning with and from each other. Participants also developed reciprocal critical friendships (Swaffield 2004), with colleagues providing nonjudgemental feedback and acting as sounding boards.

Participants' dialogue indicated that cross-phase CPD focused on AfL has particular benefits for easing pupil transfer from primary to secondary school. The working group as a whole and each of the subgroups resembled Mizelle's (2005) 'vertical team,' through which teachers realised they faced very similar issues and were helped to refine and develop their AfL practices. They also came to understand more about pupils' experiences and achievements beyond their own classes, as well as the expectations and demands in other lessons pupils attend before, after, and alongside their own. Activities focused on AfL are relevant to all teachers as AfL is cross-curricular, which may make organising cross-phase working easier than when it follows more traditional, subject-specific demarcations. Thinking about transfer to secondary school in terms of AfL also draws attention not just to the primary-secondary divide but also to the divisions among subjects in the senior school. It seems likely that if the practices of specialist subject teachers are more closely aligned, then a pupil's move from a single class teacher in primary school to multiple teachers in secondary will be smoother. AfL acts as a pedagogical unifier across subjects and age ranges. A final way in which AfL may ease transfer is through its promotion of learning autonomy, which helps pupils to be more self-regulating and to see themselves as agents of their learning, able to make sense of apparently different learning environments.

Promoting learning autonomy, along with the other two principles of making learning explicit and focus on learning rather than grades, were the conceptual framework used throughout the project. Their introduction and promotion was perhaps the academic's most significant contribution (beyond facilitating the whole process of collaborative inquiry), illustrating Lave and Wenger's (1991) recognition of the value of different roles in a community of practice. The three principles encapsulating the essence of AfL provided a focus for the entire project, a framework for analysing what can appear very disparate practice (the 'simplification' mentioned by one teacher), and a common vocabulary. They were referred to throughout the meetings, were made explicit in all the end of year workshops, and proved to be a powerful scaffold for discourse (Swaffield 2006). Evidence from this small scale project strongly suggests that a framework of principles integrated into a 
programme of professional learning and development considerably enhances its effectiveness. The three AfL principles were derived from the Learning How to Learn research (James et al. 2007), and as has been demonstrated are applicable across subjects, age ranges and contexts; in other words, they exhibit key characteristics identified by Bruner (1966) - power and economy. The formulation and use of principles to guide practice has a long pedigree in education: for example Stenhouse advocated their use in his seminal work in 1975, that included reference to Peters' (1959) discussion of principles of procedure. A more recent example is the Leadership for Learning framework with its five principles for practice developed through an international project (MacBeath and Dempster 2009) that have directly influenced policy and practice in many contexts across the world (Swaffield et al. 2014).

The project was led overall by a senior leader from the secondary school, in partnership with the head teachers of all the schools and a steering group. The senior leader liaised closely with the academic who had a major role in facilitating the working group and contributing to the joint staff meetings. Undoubtedly, the history and culture of collaborative working among the cluster schools and with the university helped the smooth running of the project. Another essential was the funding secured by the project coordinator which released teachers during the school day for working group meetings, provided refreshments for these and the joint cluster staff meetings, and enabled the academic's involvement. Limited funding only goes so far, and great benefit was derived from goodwill, resting on trust and commitment, and often made manifest by support in kind (for example subgroups' additional meetings, rooms, and research). Leadership decisions to include teachers across the spectrum of experience and seniority both built on and enhanced trust, and saw colleagues ranging from a newly qualified teacher to a head teacher all learning from and with each other. This developed all of Putnam's (2000) and Woolcock's (2001) forms of social capital—bonding, bridging, and linking.

\subsubsection{The Challenges for Implementation}

Notwithstanding all the advantages of cross-phase AfL-focused professional development, there are considerable challenges.

- Collaborative time. It takes time to develop the understanding and trust needed for collaborative professional learning, especially with colleagues from different contexts.

- Duration. One academic year is too short to embed changes in AfL practice, yet other topics (albeit related) arise deserving of attention.

- Funding. Enabling teachers to meet together, especially when they come from different schools, costs money and limits the number who can be directly involved. 
- Coordination and goodwill. Overall coordination is best done by one or two people, and goodwill from everyone helps overcome the inevitable difficulties.

- Unifying principles are needed to bring conceptual clarity and coherence, and to aid dialogue of what could otherwise be seen as widely disparate and unrelated practices.

- Sustaining and scaling remain perennial challenges.

\subsubsection{Recommendations}

The research reported here involved just one secondary school and its feeder primary schools, so considerable caution is necessary when making generalised recommendations. Moreover, these schools had a history of collaboration, school leaders valued and supported the project, and the local culture was conducive to cross-school working. Nevertheless, the findings of this study suggest a number of points for consideration by teachers, policymakers, and particularly school leaders more widely.

Since it appears that teachers' AfL practices can be enhanced through working with colleagues in different contexts, teachers generally might be advised to take and create every opportunity to do so. This is much easier when such working arrangements are valued and facilitated by school leaders, ensuring practical coordination and providing necessary funding.

Research-generated, parsimonious principles may well enhance the efficacy of professional learning activities. The AfL principles identified by James et al. (2007) certainly resonated with the teachers involved in this project and thus gained further endorsement. It seems likely therefore that other teachers will also find that the three principles of making learning explicit, promoting learning autonomy, and focusing on learning rather than grades, provide a powerful conceptual framework. For school leaders these principles offer a warranted structure for the planning, review, and evaluation of AfL practices and policy. Senior teachers who were members of the working groups attested to the value of the principles, suggesting that school leaders would be advised to practise principle-directed AfL themselves, thus deepening their appreciation and understanding of assessment for learning and its underpinning principles.

The potential of AfL as a pedagogical unifier assisting pupil transfer between schools, and the benefits of teachers working with colleagues from other schools, indicate that cross-phase AfL-focused professional development is a commendable practice. It is predominantly school leaders who are in the position to set up local working groups, recognising that it takes considerable time to establish the necessary trust and understanding.

Whilst much can be achieved at the local level, national policy and guidance influence the prevailing culture. Policymakers could encourage ongoing, cross-phase collaborative development work focused on assessment for learning, 
not least by avoiding frequent changes in national assessment arrangements so that school leaders and teachers can concentrate on AfL. Given the encouraging outcomes of this small scale study, further research into similar cross-phase professional development would be welcome.

\section{References}

Beaumont, C., Moscrop, C., \& Canning, S. (2014). Easing the transition from school to HE: Scaffolding the development of self-regulated learning through a dialogic approach to feedback. Journal of Further and Higher Education, Published online October 09, 2014. doi:10.1080/0309877X.2014.953460

Black, P., \& Wiliam, D. (1998). Assessment and classroom learning. Assessment in Education: Principles, Policy \& Practice, 5(1), 7-74.

Borko, H. (2004). Professional development and teacher learning: Mapping the terrain. Educational Researcher, 33(8), 3-15.

Bruner, J. (1966). Towards a theory of instruction. Cambridge, Massachusetts: Harvard University Press.

Clausen, K. W., Aquino, A.-M., \& Wideman, R. (2009). Bridging the real and ideal: A comparison between learning community characteristics and a school-based case study. Teaching and Teacher Education, 25(3), 444-452.

Cooper, C., \& Boyd, J. (1998). Creating sustained professional growth through collaborative reflection. In C. M. Brody \& N. Davidson (Eds.), Professional development for cooperative learning: Issues and approaches. Albany: State University of New York Press.

Craven, R. G., Marsh, H. W., \& Debus, R. L. (1991). Effects of internally focused feedback and attributional feedback on enhancement of academic self-concept. Journal of Educational Psychology, 83(1), 17-27.

Darling-Hammond, L. (1996). What matters most: A competent teacher for every child. The Phi Delta Kappan, 78(3), 193-200.

Earl, L. (2012). Assessment as learning (2nd ed.). Thousand Oaks, California: Corwin Press.

Galton, M., Gray, J., \& Rudduck, J. (2003). Transfer and transitions in the middle years of schooling (7-14): Continuities and discontinuities in learning (No. 443). Annesley: Department of Education and Science.

Gardner, J. (2006). Assessment for learning: A compelling conceptualization. In J. Gardner (Ed.), Assessment and learning. London: Sage.

Gardner, J. (2010). Teachers as self-agents of change. In J. Gardner, W. Harlen, L. Hayward, G. Stobart, \& M. Montgomery (Eds.), Developing teacher assessment. Maidenhead: Open University Press, McGraw-Hill Education.

Ginsburg-Block, M. D., Rohrbeck, C. A., \& Fantuzzo, J. W. (2006). A meta-analytic review of social, self-concept, and behavioral outcomes of peer-assisted learning. Journal of Educational Psychology, 98(4), 732-749.

Hargreaves, E. (2005). Assessment for learning? Thinking outside the (black) box. Cambridge Journal of Education, 35(2), 213-224.

James, M., Black, P., Carmichael, P., Drummond, M.-J., Fox, A., MacBeath, J., et al. (2007). Improving learning how to learn: Classrooms, schools and networks. London: Routledge.

James, M., \& McCormick, R. (2009). Teachers learning how to learn. Teaching and Teacher Education, 25(7), 973-982.

James, M., \& Pedder, D. (2006). Beyond method: Assessment and learning practices and values. Curriculum Journal, 17(2), 109-138.

Katz, S., \& Earl, L. (2010). Learning about networked learning communities. School Effectiveness and School Improvement, 21(1), 27-51. 
Kellard, K., Costello, M., Godfrey, D., Griffiths, E., \& Rees, C. (2008). Evaluation of the developing thinking and assessment for learning development programme. Birmingham: Report for BMG research.

Kennedy, A. (2014). Understanding continuing professional development: The need for theory to impact on policy and practice. Professional Development in Education, 40(5), 688-697.

Lave, J., \& Wenger, E. (1991). Situated learning: Legitimate peripheral participation (1st ed.). Cambridge, UK: Cambridge University Press.

Little, J. (2005). Professional learning and school-network ties: Prospects for school Improvement. Journal of Educational Change, 6(3), 277-284.

MacBeath, J., \& Dempster, N. (Eds.). (2009). Connecting leadership and learning: Principles for practice. Abingdon, UK: Routledge.

Miller, D., \& Lavin, F. (2007). 'But now I feel I want to give it a try': Formative assessment, self-esteem and a sense of competence. The Curriculum Journal, 18(1), 3-25.

Mizelle, N. B. (2005). Moving out of middle school. Educational Leadership, 62(7), 56-60.

Pedder, D., \& Opfer, V. D. (2011). Are we realising the full potential of teachers' professional learning in schools in England? Policy issues and recommendations from a national study. Professional Development in Education, 37(5), 741-758.

Peters, R. S. (1959). Authority, responsibility and education. London: Allen \& Unwin.

Putnam, R. (2000). Bowling alone: The collapse and revival of American community. New York: Simon \& Schuster Ltd.

Rosenholtz, S. (1989). Teacher's workplace: The social organization of schools. New York: Longman.

Sato, M., Coffey, J., \& Moorthy, S. (2005). Two teachers making assessment for learning their own. Curriculum Journal, 16(2), 177-191.

Smith, K. (2011). Professional development of teachers-A prerequisite for AfL to be successfully implemented in the classroom. Studies in Educational Evaluation, 37(1), 55-61.

Smith, K., \& Engelsen, K. S. (2013). Developing an assessment for learning (AfL) culture in school: The voice of the principals. International Journal of Leadership in Education, 16(1), 106-125.

Stenhouse, L. (1975). An introduction to curriculum research and design. London: Heinemann.

Suurtamm, C., Koch, M., \& Arden, A. (2010). Teachers' assessment practices in mathematics: Classrooms in the context of reform. Assessment in Education: Principles, Policy \& Practice, 17(4), 399-417.

Swaffield, S. (2004). Critical friends: Supporting leadership, improving learning. Improving Schools, 7(3), 267-278.

Swaffield, S. (2006). Scaffolding discourse in multi-national collaborative enquiry: The carpe vitam leadership for learning project. Leading \& Managing, 12(2), 10-18.

Swaffield, S. (2011). Getting to the heart of authentic assessment for learning. Assessment in Education: Principles, Policy and Practice, 18(4), 433-449.

Swaffield, S., Dempster, N., Frost, D., \& MacBeath, J. (Eds.) (2014). LfL travels. InForm 17. University of Cambridge.

Swaffield, S., \& MacBeath, J. (2006). Embedding learning how to learn in school policy: The challenge for leadership. Research Papers in Education, 21(2), 201-215.

Tierney, R. D. (2006). Changing practices: Influences on classroom assessment. Assessment in Education: Principles, Policy \& Practice, 13(3), 239-264.

Wenger, E. (1998). Communities of practice: Learning, meaning, and identity. Cambridge, U.K.: Cambridge University Press.

Wiliam, D. (2007a). Changing classroom practice. Educational Leadership, 65(4), 36-42.

Wiliam, D. (2007b). Content then process: Teacher learning communities in the service of formative assessment. In D. B. Reeves (Ed.), Ahead of the curve: The power of assessment to transform teaching and learning (pp. 183-204). Bloomington, Indiana: Solution Tree.

Wiliam, D. (2009). Assessment for learning: Why, what and how? An inaugural lecture by Dylan Wiliam. London: Institute of Education. 
Willis, J., Adie, L., \& Klenowski, V. (2013). Conceptualising teachers' assessment literacies in an era of curriculum and assessment reform. Australian Educational Researcher, 40(2), 241-256.

Woolcock, M. (2001). The place of social capital in understanding social and economic outcomes. ISUMA: Canadian Journal of Policy Research, 2(1), 11-17. 